\title{
Technology, Civic Engagement and Street Science
}

\author{
Hacking the Future of Participatory Street Design in the Era of Self-Driving Cars
}

\author{
William Riggs \\ University of San Francisco \\ San Francisco, California \\ wriggs@usfca.edu
}

\begin{abstract}
Emerging technologies are fundamentally changing how we plan, develop, and manage our cities. Given trends of increasing mobile use, local governments are being required to adopt and use new technologies to plan, communicate and engage with citizens. In this context, this study then hypothesizes how technology trends will continue to impact planning and local government using the case of the participatory planning application ReStreet.com (app.restreet.com), a tool for visioning the future of streets in a future of autonomous or self-driving vehicles. While other work has detailed the importance of technology in the participatory process, this tool provides an example of how methods of digital representation and new technology can enrich community participation and democratize the planning process.
\end{abstract}

\section{CCS CONCEPTS}

- Human-centered computing $\rightarrow$ Information visualization;

\section{KEYWORDS}

ACM proceedings, urban technology, public participation, responsive design, civic hacking

\section{ACM Reference Format:}

William Riggs. 2018. Technology, Civic Engagement and Street Science: Hacking the Future of Participatory Street Design in the Era of Self-Driving Cars. In dg.o '18: dg.o 2018: Proceedings of the 19th Annual International Conference on Digital Government Research, May 30-June 1, 2018, Delft, Netherlands. ACM, New York, NY, USA, Article 4, 6 pages. https://doi.org/10.1145/ 3209281.3209383

\section{INTRODUCTION}

According to reports by the CTIA-The Wireless Association, there were currently over 3.26 million in 2012, with over 150 million of those subscribers using a smartphone [1], [2]. The ubiquity of the mobile device has become unavoidable, and various studies have shown how mobile technology has increasingly altered various human behaviors and interactions in an urban setting [3].

These technologies not only influence the way people move throughout their communities and interact with one another, but many planners predict they will influence the way urban planners

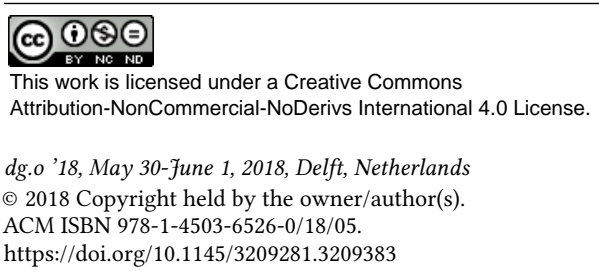

and city officials understand and interact with their citizens with increased reliance on e-government [4], [5]. Internet-enabled mobile devices incorporating GPS have allowed for location-based that can increase awareness of user activity, movements, and behaviors in real-time conditions and specific contexts [6].

These real-time conditions create an opportunity for a more legible urban landscape for the citizen, thus creating more efficient and sustainable mobility patterns throughout an urban environment [7] . At the same time, benchmarks of the use of participatory technology in cities across the United States, evaluating recent changes in how the top 500 cities in the US, suggesting high mobile use but very few mobile platforms [8]. In this new (primarily mobile) technology world, governments must plan, communicate and engage with citizens [5], [9], [10]. This is particularly acute in the area of new and emerging forms of transportation, especially focused on autonomous vehicles [11] [12].

Over the past years there have been many technological revelations that have made it clear that autonomous vehicle technology will become increasingly prevalent in our communities. Yet there is a high degree of uncertainty about how this new technology will outlay in urban environs. While there is ample discussion over the anticipated pros and cons of this technology [13]-[15], very little work has been given to decision-making in this high uncertainty environment-especially given that land use and transportation actions have long inertial properties [12], [16]. In terms of urban policy, research has indicated that only 2 of the 25 largest metropolitan areas mention autonomous or connected vehicles their planning documents [11]. And despite some wide level policy suggestions from organizations such as the Rand Corporation and consultants like Parsons, planning policy appears to be lagging technological growth.

This article provides a background that ties together the mobile, mobility-on-demand and autonomous transportation revolutions with a need for increased participatory planning. It then discusses the ReStreet planning tool as way to engage the topic and provide a case on how cities can democratize street planning, hacking streets in the autonomous future.

\section{BACKGROUND}

\subsection{The Mobile Revolution}

We have become a mobile society. Academics argue that the mobile phone has rapidly evolved into an object with which people have developed a personal relationship [17], and mobile phones have been noted as a symbol of aggressive individualism [18], [19]. The use of a mobile phone has been viewed as an isolating activity, in which people can create a personal "bubble" around them when talking on the phone [20], [21]. 
In this context some have noted how mobile technology and other information community technologies support the creation of a diverse network social media system [22], which can create a variety of new social interactions. According to a Pew Internet Poll done in 2013, 72\% of Internet users stated that they use social networking sites, including $40 \%$ of cell phone owners. This locationbased SNS data can be extremely useful for urban planners in that it can be analyzed to make assumptions about citizens' behavioral patterns and preferences in urban environments.

Townsend [23] argues how the time-management capabilities of mobile phones are essentially quickening the pace of urban life, which increases the metabolism of urban systems. Such an understanding of how mobile technologies alter human behaviors could help planners anticipate how these changes could transform neighborhoods, cities and regions. Research shows that many planners use their personal or work smartphone for business purposes [9], [24].

For example, the fusion of mobile and GIS technology is becoming available to citizens who have the capabilities of become contributors into a public process of planning and to do community development [25]-[28]. Other work has shown opportunities for 'micro-participation' and integration of face-to-face with computer mediated collaboration in planning processes [29], [30].

Despite the promise such technology holds, there has been limited growth of technology in local government. While mobile technology creates its own barrier towards those who are unfamiliar with the technology or who lack easy access to computer resources [31], many times government lags in technology adoption, stuck in oppressive cycles of technological systems [32]. This can create disparity in access and equity issues between those with and without access [33] and differences in citizen participation [34]. Some have suggested that even with new epistemological approaches patterns of technology use, competency, and access within local communities will remain socioeconomically segregated [35], [36]. As shown in Figure 1, on $15 \%$ of the top 500 cities in the US use mobile-phone friendly technology, suggesting standards for using technology in planning [8], something that may be particularly acute in our new (and largely mobile) transportation and mobility future [37].

\subsection{The Transportation Revolution}

One of the fastest growing and most invested-in transportation industries in recent years have been networked and data driven personal travel. While it originated with peer-to-peer networks that allowed for car and ride-sharing, a sophisticated industry has arisen in the era of companies like, Get-Around, Lyft and Uber. These transportation network companies (TNCs) offer variations of on-demand services for travel via individual vehicles all from a networked, mobile platform. They connect riders with drivers through mobile smartphone apps, allowing point-to-point travel similar to a taxi service [38].

Because such services allow for convenient point-to-point mobility, some say they have the potential to reduce automobile ownership in urban areas with the potential to facilitate first and last mile connections [38], [39] and compliment transit [40]. Other work has suggested that this smart and connected form of mobility actually
Mobile-Friendly Responsive Design Use

By City Planning Dept. Websites

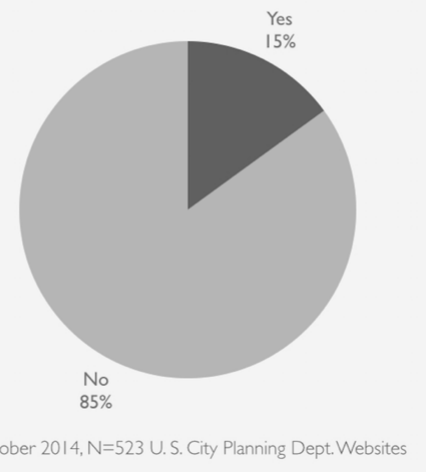

Figure 1: Mobile friendliness in the US (Source: Riggs 2016).

reduces public transit ridership and increase VMT [41], and created complicated pick up and drop off issues [42].

The TNC revolution is compounded and is underscored by moves toward autonomous vehicles [43]. As self-driving cars are getting smarter and merging with our devices, there are clear opportunities to shape advances in transportation, to and harness them to reshape cities and improve the socio-economic health of cities[44]. There are opportunities to reduce collisions and improve access to healthcare and to connect individuals to jobs and change the way cities organize space and optimize trips [11], [13].

That said, there are also challenges and little understanding of how travel behavior and streets will change in this brave new world. Some work has used chauffeur-based experiments to try to test behavior [45]-providing the best simulation of this technology thus far-and many other high-level policy documents have made suggestions and predictions, yet put simply, technological change is out-pacing transportation planning and policy.

\subsection{The (Transactive) Sharing Revolution}

Some of the most specific work combining data science and has been done on taking incremental steps to envision future streets [46]-[48]. These kind of tools which facilitate the participatory process have become an important part of the practice of planning and governance in recent years [29]. Tools that provide interactive and transactive platforms can help enrich community participation and democratize the policy-making process [9], [24]. As described by Riggs and Gordon, Taxonometrically,

"...interactive tools rely on some sort of interaction between a government agency and the public. They involve a two-way transaction of information between the local agency and the public, as citizens often want to share their thoughts regarding how things are being done in the community and what is planned in the future. Prior to web technology the citizen had limited choices- they could attend a public hearing/meeting, they could visit the planning office in person, they could call the planning office/city manager, or write a letterâĂe

Finally transactive tools involve an exchange between agencies and citizens. Many of these activities would have previously required a citizen to visit the local government offices, can now be conducted 
on-line. Some examples from planning are the purchase of copies of the Comprehensive Plan or Zoning Codes, the filing of permits, variances and appeals, and the paying of associated fees for permit and other applications. The introduction of e-Business adds a 'transactive' quality to planning web sites, that allows more efficient and costeffective transaction by automating the payment and order process."

In this context applications there are many such applications that allow for sharing/crowdsourcing and user input from a larger community that contributes to a larger body of information. This includes public input tools such as Mindmixer or economic development platforms like OppSites, or sites like SeeClickFix or GoRequest, which allow citizens to directly report issues in their neighborhood to their local governments so they can be addressed by a local agency. Yet few of these are in the transportation domain; a field being revolutionized by big data. While companies like Remix and Streetmix provide tools for user to visualize future street or transit, very few if any applications exists in the transactional domain focused on transportation planning and government input (clearly this excludes a large body of traveler information apps which fall into the Wayfinding opposed to the Transactive category based on the Riggs/Gordon Taxonomy).

\section{METHODOLOGY}

In this context this study developed and conducted two pilots using the Restreet.com (app.restreet.com). The first participatory street design pilot focused on a long-range planning process in San Luis Obispo, CA (SLO). The second provided a national audience the chance of deconstructing an urban and a suburban streetscape to represent what they may look like in a future with autonomous vehicles.

Restreet was created by William Riggs, Mike Boswell and Ryder Ross in 2016 as a code fork from the Code for America project Streetmix. The idea was to democratize the way we plan streets and synthesize that data for policy and decision-making. The streets depicted show right-of-way needs eroding due to the prevalence of autonomous vehicles creating efficiency or the policy decision to do so in advance of their adoption. An example of the interface is provided in Figure 2.

The tool was built recognizing that transportation behavior is becoming ever-more complex as digital information serves to moderate travel behavior and research has shown that community based digital tools can be effectively used to shape the built environment for walking and biking [9]. The proliferation of geospatial information provides an additional tool for influencing behavior through mobile frameworks and through digital representation tools. For example, tools like SeeClickFix and Streetmix have been used to do conceptual design of sustainable streets. Likewise tools such as Mindmixer and Brigade have been shown to increase public participation and be supportive of community-based and participatory planning (CBPP) methods [8], [29].

\subsection{Backend Software Development}

In terms of backend development, the research team used the based code from the open-source Streetmix Github repository, creating a 'fork' so we could keep track of our changes to the code. The team began with a default street layout and made this a fixed option,

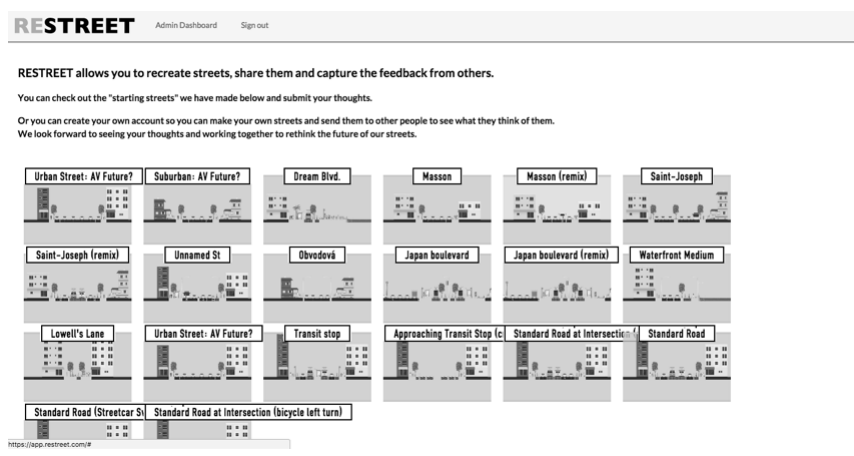

Figure 2: ReStreet Interface.

changing the default street width, the building height, the number of lanes and type of lanes to look like our case street. The team also identified which features we wanted to update or change or remove in the base Github package in order to make the tool easier to use and simpler to understand. A Submit Street feature was added, which asked the user for some basic demographic information and if they would mind being contacted / providing contact information. The database schema was altered on the backend to allow for a new 'submitted' Boolean and record the submitted street. The team also included an API endpoint to bundle the submissions, and send an email out and update the website with immediate feedback.

\subsection{Analysis}

The deployment and data collection the team aggregated and analyzed the submissions that were received. To do this the team wrote a number of MongoDB database queries on the entries that had been logged to find out information including: How many streets were submitted; How many lanes were used; How many submitted streets had bike lines, parklets; How many streets had no parking. While this was done manually for Pilot 1, SLO Community Outreach, the data tabulation was automated for Pilot 2, a project on street design for autonomous vehicles .
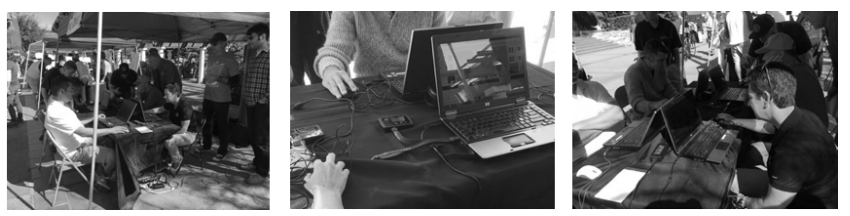

Figure 3: Onsite Deployment Method for Pilot 1 in SLO.

\subsection{Context: SLO Community Outreach}

In 2016 a researcher undertook a pilot street design project as a part of the Vision San Luis Obispo project in San Luis Obispo, CA. The project involved deploying an initial version of ReStreet (which we called StreetPlan originally) using a case study street in the City of San Luis Obispo. The objective was to capture data from citizens about what the future vision for that street, space or urban area-articulating how the public at large prefers and how they want to allocate active transportation resources in that location. With a product such as Streetmix existing, they did not allow us 
to capture public input and to aggregate this for decision-making and planning purposes, as they were not transaction in nature. The ReStreet tool allowed for us to engage participants on street priorities and then to combine those priorities to show community preferences. The goal of providing these community priorities and trade offs was to inform street section planning, design and traffic modeling / simulation. Ultimately it provided a community-based process for getting cities to get a data-driven pulse on community preferences and to articulate those results online and in plans.

As data was gathered at a public event where our team was available to assist with any issues, the team set up a bank of computers with wifi-enabled hotspots for the public to congregate and submit their 'street plans' as pictured in Figure 3. While the team anticipated that the tool could be used to collect data in a virtual environment we cannot underscore enough the power of using it in an onsite, community-centric environment.

While the tool could be used to collect information beyond the event, based on our experience the process of having citizens work through design options alongside others was very useful. People engaged in important discussions on the trade-offs faced (e.g. if you have more space dedicated to bicycles then that leaves less space not only for cars but for pedestrians), and made decisions based on those discussions; grappling with these issues in parallel with others.

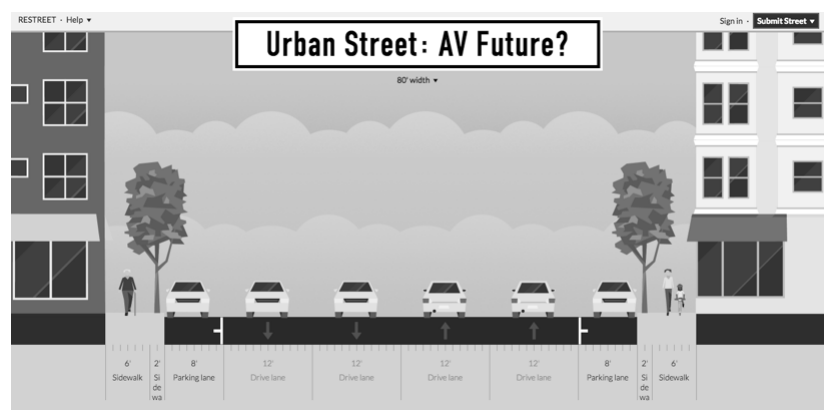

Figure 4: Urban Street Section to be Redesigned for the Autonomous Future.

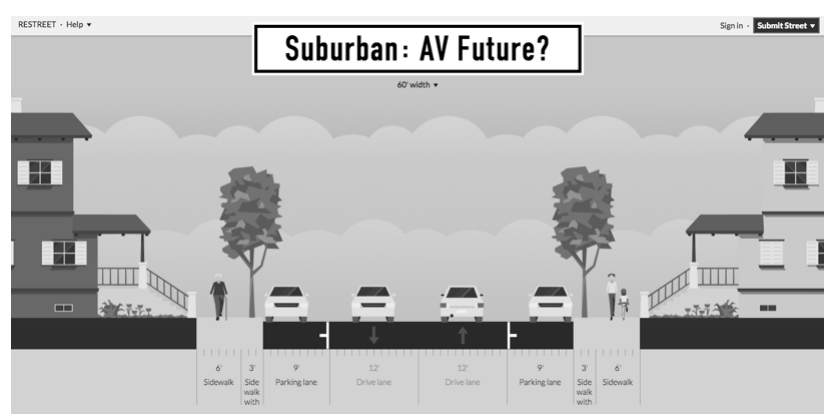

Figure 5: Suburban Street Section to be Redesigned for the Autonomous Future.

\subsection{Context: Design For Autonomous Vehicles}

The second pilot grappled with the more pressing issue, designing streets for the autonomous vehicle and deconstructed an urban and a suburban streetscape using the ReStreet tool. Again, the idea was to democratize the way we plan streets and synthesize that data for policy and decision-making. The streets depicted show right-of-way needs eroding due to the prevalence of autonomous vehicles creating efficiency or the policy decision to do so in advance of their adoption. The two prototypical street platforms used for participatory feedback are provided in the Figures 4 and 5 .

\section{RESULTS}

\subsection{Pilot 1: SLO Community Outreach}

In the case of the first pilot, over 300 participants offered feedback using the tool. This data indicated that two-thirds preferred more bike lanes and half wider sidewalks in the downtown streets. As is shown in Figure 6, there was a desire across the board to see more multi-modal transportation amenities, but this did not extend to eliminating parking. The data indicated a strong preference toward a scenario with 1 one-way, drive lane, with parking on both sides. The influence of the tool was that it: supported development of new downtown street type definitions; influenced research and recommendations of mobility team; and ended up being reflected in draft streetscape designs. This aggregated data is depicted in Figure 7.

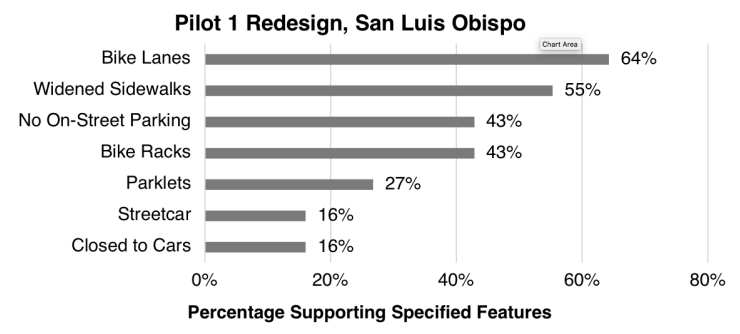

Figure 6: Frequency of responses by streets amenities desired in participatory Pilot 1.

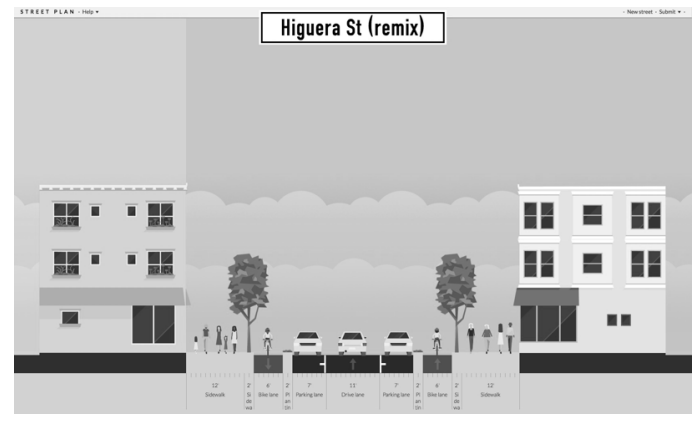

Figure 7: Aggregated street data in visual format from the Pilot 1 experiment in San Luis Obispo. 
One unique finding from the participatory nature of this pilot, was the importance of interaction. First, as stated in the methods, data was collected at a public event where a team was available to assist with the planning process. This allowed not only for deliberation and exchange of opposing views, but for compromise-all important factors in governance. It also allowed the participants to make trade-offs and to work on design options together-in true citizen engagement. Second, it allowed for members of the population who were less tech savvy to get help. These were unique to to the SLO pilot and not present in Pilot 2.

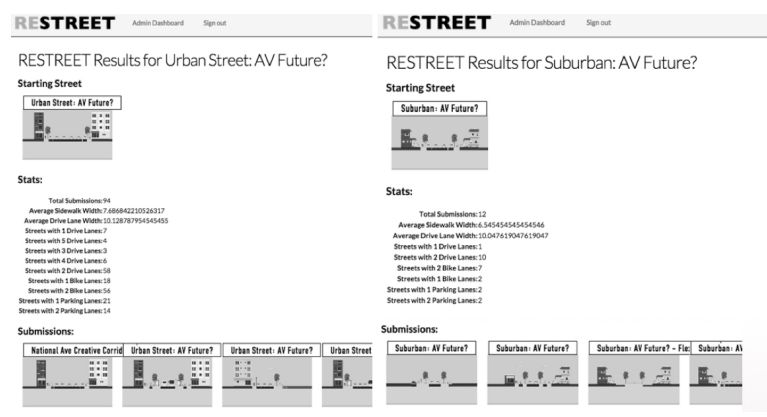

Figure 8: Participatory data from Pilot 2 urban $(n=94)$ and suburban $(n=12)$ experiment on the future streets of autonomous vehicles.

\subsection{Pilot 2: Design for Autonomous Vehicles}

In the case of Pilot 2, as shown in the side-by-side screenshots in Figure 8 , in both urban and suburban future scenarios respondents wanted streets that were more-narrow and had fewer lanes. While the responses for the two street typologies were uneven (8 times more people provided feedback on the urban vs. suburban street; $\mathrm{N}=94$ as opposed to $\mathrm{N}=12$ ), there was a cross-sectional desire for lanes around 10 feet in an autonomous future. Further, as shown in Figure 8, particularly for the typical urban section, there was a strong desire to see fewer lanes of traffic. The most frequent response, for almost two-thirds of respondents, was that they would like to see 2 drive lanes on former 4-lane roads-something that may be achievable in the future due to operational efficiencies of autonomy, but is achievable now for cities that want to invest in road diets and extend road right-of-way for bicyclists and pedestrians.

Beyond these results, it is worth noting something unique that occurred that was beyond the scope of the pilot. Although only 100 individuals responded to the initial query to participate in the street-design-for-the-autonomous-vehicle exercise, thousands of users began submitting their own streets and sharing them with friends. Over 8,000 street submissions were made on the site in a period within a 4-month period. Although this result is limited in that people could submit multiple times and may not have been able to get help if they did not understand the tool (something the SLO pilot provided), this results suggests latent demand for transactive and participatory transportation tools.

\section{CONCLUSIONS}

This paper explores two pilot deployments of the ReStreet app (app.restreet.com) and finds that online transactive tools in the transportation realm can not only be effective from a participatory planning standpoint, but that they can help supports traffic calming and lane reductions that might be synergistic with future transportation advancement. In both cases there was a very clear and data driven public sentiment for the future of what a street can and should look like.

Furthermore this work shows that there is ample room in the future to expand and bring this type of technology to the community. Given appropriate marketing and extended development, there are between 30 and 80 cities in the US that could be interested in such a software-as-a-service to increase participation over the next 1-2 years based on the number of cities in the US conducting streetscape plans.

Next steps in extending this work might be to conduct further refinement on the tools and to begin work with other cities who want to engage the public with reshaping streets. Furthermore, there is room for applied academic work that tests the efficacy of such tech tools, and how they can better translate plans to action. Ultimately research should validate if they are effective helping to achieve more safe and sustainable streets for all.

\section{ACKNOWLEDGMENTS}

The field work for this project was conducted in partnership with researchers Michael Boswell of Cal Poly San Luis Obispo and Ryder Ross of Ross Web Consulting. Code for America provides access to original code, one of the original Streetmix programmers (Lou Huang) provided ideas and support. Tammy Seale and Lorelli Cappel, and many Cal Poly Students helped deploy the SLO pilot.

\section{REFERENCES}

[1] CTIA, "US wireless quick facts," Available: https://www.ctia.org/ [Accessed 12 June 2010.]

[2] M. Mandel and M. C. P. Judith Scherer, "The Geography of the App Economy," CTIA Wirel. Assoc., 2012.

[3] A. Carrel, V. Ekambaram, D. Gaker, R. Sengupta, and J. L. Walker, "The Quantified Traveler: Changing transport behavior with personalized travel data feedback," 2012.

[4] J. Evans-Cowley and M. Manta Conroy, "The growth of egovernment in municipal planning," J. Urban Technol., vol. 13, no. 1, pp. 81-107, Apr. 2006.

[5] J. Evans-Cowley, "Planning in the Real-Time City: The Future of Mobile Technology," J. Plan. Lit., vol. 25, no. 2, pp. 136-149, Nov. 2010.

[6] H. Kwak, C. Lee, H. Park, and S. Moon, "What is Twitter, a social network or a news media?," in Proceedings of the 19th international conference on world wide web, 2010, pp. 591-600.

[7] R. Ling, The Mobile Connection: The Cell Phone's Impact on Society. Morgan Kaufmann, 2004.

[8] W. Riggs, "Mobile responsive websites and local planning departments in the US: Opportunities for the future," Environ. Plan. B Plan. Des., p. 265813516656375, Jul. 2016.

[9] W. Riggs and K. Gordon, "How is mobile technology changing city planning? Developing a taxonomy for the future," Environ. Plan. B Plan. Des., p. 265813515610337, Oct. 2015. 
[10] C. S. Slotterback, "Planners' perspectives on using technology in participatory processes," Environ. Plan. B Plan. Des., vol. 38, no. 3, pp. 468-485, 2011.

[11] E. Guerra, "Planning for Cars That Drive Themselves Metropolitan Planning Organizations, Regional Transportation Plans, and Autonomous Vehicles," J. Plan. Educ. Res., p. 0739456X15613591, Nov. 2015.

[12] W. W. Riggs and M. R. Boswell, "No Business as Usual in an Autonomous Vehicle Future," Planetizen.com, 2016.

[13] D. J. Fagnant and K. M. Kockelman, "The travel and environmental implications of shared autonomous vehicles, using agent-based model scenarios," Transp. Res. Part C Emerg. Technol., vol. 40, pp. 1-13, 2014.

[14] T. Litman, "Autonomous Vehicle Implementation Predictions," Vic. Transp. Policy Inst., Vol. 28, 2014.

[15] S. Thrun, "Toward robotic cars," Commun. ACM, vol. 53, no. 4, pp. 99-106, 2010.

[16] W. Riggs and M. R. Boswell, "Thinking Beyond the (Autonomous) Vehicle: The Promise of Saved Lives," Planetizen.com, 2016.

[17] J. E. Katz, "Social and organizational consequences of wireless communications: a selective analysis of residential and business sectors in the United States," Telemat. Inform., vol. 14, no. 3, pp. 233-256, 1997.

[18] J. Harkin, Mobilisation: The Growing Public Interest in Mobile Technology. Demos, 2003.

[19] L. Srivastava, "Mobile phones and the evolution of social behaviour," Behav. Inf. Technol., vol. 24, no. 2, pp. 111-129, 2005.

[20] C. Bassett, "How Many Movements? Mobile Telephones and Transformations in Urban Space," Open, vol. 9, pp. 38-47, 2005.

[21] K. Gergen, The saturated self: Dilemmas of identity in contemporary life. Basic books, 1991.

[22] K. N. Hampton, L. F. Sessions, and E. J. Her, "Core networks, social isolation, and new media: How Internet and mobile phone use is related to network size and diversity," Inf. Commun. Soc., vol. 14, no. 1, pp. 130-155, 2011.

[23] A. M. Townsend, "Life in the real-time city: Mobile telephones and urban metabolism," J. Urban Technol., vol. 7, no. 2, pp. 85-104, 2000.

[24] J. Evans-Cowley and B. Kubinski, "A Brave New World: How Apps Are Changing Planning," Planetizen.com, 2014.

[25] M. Craglia et al., "Digital Earth 2020: towards the vision for the next decade," Int. J. Digit. Earth, vol. 5, no. 1, pp. 4-21, 2012.

[26] G. Goggin and J. Clark, "Mobile phones and community development: a contact zone between media and citizenship," Dev. Pract., vol. 19, no. 4-5, pp. 585-597, 2009.

[27] D. M. Simpson, "Virtual Reality and Urban Simulation in Planning: A Literature Review and Topical Bibliography," J. Plan. Lit., vol. 15, no. 3, pp. 359-376, Feb. 2001.

[28] D. Sui and M. Goodchild, "The convergence of GIS and social media: challenges for GIScience," Int. J. Geogr. Inf. Sci., vol. 25, no. 11, pp. 1737-1748, 2011.

[29] J. Evans-Cowley and G. Griffin, "Microparticipation with Social Media for Community Engagement in Transportation Planning," Transp. Res. Rec. J. Transp. Res. Board, vol. 2307, pp. 90-98, Dec. 2012.
[30] G. Zurita and N. Baloian, "Mobile, Collaborative Situated Knowledge Creation for Urban Planning," Sensors, vol. 12, no. 5, pp. 62186243, 2012.

[31] A. P. Ray, "Planning Connected: Using Online Social Networks to Improve Knowledge about Places and Communities," 2011.

[32] B. Pitkin, "A Historical Perspective of Technology and Planning," Berkeley Plan. J., vol. 15, no. 1, Jan. 2001.

[33] J. Fernback and G. Shaffer, "Urban Planning Unplugged: How Wireless Mobile Technology Is Influencing Design Elements in Seven Major US Cities," Commun. Assoc. Inf. Syst., vol. 27, no. 1, p. 35, 2010.

[34] E. Seltzer and D. Mahmoudi, "Citizen Participation, Open Innovation, and Crowdsourcing: Challenges and Opportunities for Planning," J. Plan. Lit., p. 885412212469112, Dec. 2012.

[35] J. D. Guzzetta and S. A. Bollens, "Urban Planners Skills and Competencies Are We Different from Other Professions? Does Context Matter? Do We Evolve?," J. Plan. Educ. Res., vol. 23, no. 1, pp. 96-106, 2003.

[36] C. J. Seeger, "The role of facilitated volunteered geographic information in the landscape planning and site design process," GeoJournal, vol. 72, no. 3-4, pp. 199-213, Aug. 2008.

[37] W. Riggs, C. Steins, and A. Chavan, "City Planning Department Technology Benchmarking Survey 2015," Planetizen.com, 2015.

[38] L. Rayle, D. Dai, N. Chan, R. Cervero, and S. Shaheen, "Just a better taxi? A survey-based comparison of taxis, transit, and ridesourcing services in San Francisco," Transp. Policy, vol. 45, pp. 168-178, Jan. 2016.

[39] S. Shaheen and N. Chan, "Mobility and the Sharing Economy: Potential to Facilitate the First-and Last-Mile Public Transit Connections," Built Environ., vol. 42, no. 4, pp. 573-588, 2016.

[40] C. L. Rassman, "Regulating rideshare without stifling innovation: Examining the drivers, the insurance gap, and why Pennsylvania should get on board," Pitt J Tech Pol, vol. 15, p. 81, 2014.

[41] R. R. Clewlow and G. S. Mishra, "Disruptive Transportation: The Adoption, Utilization, and Impacts of Ride-Hailing in the United States," University of California, Davis, Institute of Transportation Studies, Davis, CA, Research Report UCD-ITS-RR-17-07, 2017.

[42] W. W. Riggs, M. R. Boswell, and S. Zoepf, "A New Policy Agenda for Autonomous Vehicles: ItâĂŹs Time to Lead Innovation," Planetizen.com, 2017.

[43] N. Larco, "When Are AVs Coming?" Urbanism Next, 2017. [44] H. Lipson and M. Kurman, Driverless: Intelligent Cars and the Road Ahead. MIT Press, 2016.

[45] M. Harb, Y. Xiao, and J. Walker, "Projecting Travelers into a World of Self-Driving Cars: Naturalistic Experiment for Travel Behavior Implications," in Proceedings of the 97th Transportation Research Board, Washington D.C., 2018.

[46] W. Riggs, M. R. Boswell, and R. Ross, "Streetplan: Hacking Streetmix for Community-Based Outreach on the Future of Streets," Focus, Vol. 13, vol. 13, p. 59, 2016.

[47] W. W. Riggs, "Modeling Future Street Options in an AV Future Using Restreet," 2017.

[48] M. Schlossberg, W. W. Riggs, A. Millard-Ball, and E. Shay, "Rethinking the Street in an Era of Driverless Cars," UrbanismNext, 2018. Available: https://urbanismnext.uoregon.edu/2018/01/25/newreport-rethinking-the-street-in-an-era-of-driverless-cars/. 